\section{Case Reports in Ophthalmology}

Case Rep Ophthalmol 2017;8:421-424

This article is licensed under the Creative Commons Attribution-NonCommercial 4.0 International License (CC BY-NC) (http://www.karger.com/Services/OpenAccessLicense). Usage and distribution for commercial purposes requires written permission.

\title{
Swollen Optic Disc and Sinusitis
}

\author{
Chiara Del Noce $^{\mathrm{a}} \quad$ Filippo Marchi $^{\mathrm{b}} \quad$ Giacomo Sollini $^{\mathrm{b}} \quad$ Michele Iester $^{\mathrm{a}}$ \\ ${ }^{a}$ Anatomical-Clinical Laboratory for Functional Diagnosis and Treatment of Glaucoma and \\ Neuroophthalmology, Eye Clinic, DiNOGMI, University of Genoa, Genoa, Italy; \\ ${ }^{b}$ Otorhinolaryngology Clinic, University of Genoa, Genoa, Italy
}

\section{Keywords}

Optic disc swelling $\cdot$ Sinusitis

\begin{abstract}
Purpose: To present a case of optic disc swelling caused by sinusitis. Methods: Ocular symptoms were investigated using computed tomography imaging of the facial bones to detect the relationship between the sinus inflammation and the optic nerve. Results: A particular configuration of the optic nerve was detected. Optic nerve course through the inflamed sphenoidal sinus is a condition associated with a greater risk of inflammation. Conclusion: Sinusitis is a rare but treatable cause of optic neuritis. The choice of the correct radiological investigation to be done to set up a proper treatment of the sinus pathological condition is also essential for the resolution of ocular symptoms.

(C) 2017 The Author(s) Published by S. Karger AG, Basel
\end{abstract}

\section{Introduction}

Optic disc swelling is a pathological condition with a variety of causes. The clinical features associated with unilateral optic disc swelling are papillitis, nonarteritic anterior ischemic optic neuropathy, compressive optic neuropathy, retinal vein occlusion, diabetic optic neuropathy, and infection or inflammation of the contiguous sinus or the orbit [1].

Paranasal sinus disease can cause a condition that mimics demyelinating optic neuritis, with acute optic neuropathy and pain on eye movements, or can cause progressive optic 
neuropathy resulting from compression. Optic neuropathy due to sinusitis and mucocele should be considered in patients who have clinical evidence of optic neuritis with seemingly atypical features, particularly in elderly patients with severe sinus disease, a history of fevers, ophthalmoplegia, or progression of vision loss beyond 2 week [2]. nusitis.

In this report we present a patient with unilateral optic disc swelling and a history of si-

\section{Case Report}

A 32-year-old female was referred to our center with acute visual deterioration in the right eye following right-sided frontal headache and retrobulbar pain. Physical examination as well as family and personal history were normal, except for a single episode of iridocyclitis well treated with corticosteroids 5 years earlier. There was no history of trauma or drug intake, and she was a nonalcoholic and a nonsmoker. The visual loss was nonprogressive and there was no history of color desaturation; neither did she have pain with ocular movements.

Complete blood work, sedimentation rate, and urinalysis were performed, and all results were normal. Best corrected visual acuity at the first visit in the right eye was 6/10. No afferent pupillary defect was present. Extraocular muscle movements were full in both eyes. At slit lamp examination the anterior segment was normal and the intraocular pressure was $16 \mathrm{~mm} \mathrm{Hg}$. At fundus examination the patient presented a unilateral swollen optic disc in the right eye (Fig. 1).

A standard automated perimetry (Humphrey 24-2) was performed which showed no field defect in both eyes. We suggested computed tomography (CT) without contrast of the paranasal sinuses to identify the cause of pressure on the right optic nerve. It showed enlarged and inflamed sinuses as well as an anatomical peculiarity: in the axial and coronal CT scans (Fig. 2) we found the optic nerve to run through the inflamed sphenoidal sinus rather than simply adjacent to it, a condition associated with partial dehiscence of the optic nerve, which translates into a greater exposure to inflammation of the nerve. The patient was started on systemic steroids therapy for 1 week (aerosol therapy with $\mathrm{N}$-acetylcysteine and budesonide). At 1-month follow-up her vision had improved from 6/10 to 9/10, contrast and color sensibility were normal, the pupils were equal and reacting to light, and ocular movements were normal as well. However, fundus examination was still abnormal, showing a diffusely swollen optic disc with undefined margins in the right eye.

\section{Discussion}

The optic nerve contains retinal ganglion cell axons that extend posteriorly from the globe through the orbit and optic canal to reach the optic chiasm. An injury to the optic nerve anywhere along this pathway by an extrinsic lesion is termed compressive optic neuropathy. The optic nerve is most vulnerable to injury where it runs adjacent to bone or in a confined space like the orbital apex or optic canal. A delay in diagnosis is not uncommon since the vision loss is insidious and the clinical findings may be missed [3]. With the sensitivity and specificity of modern neuroimaging, a negative scan essentially rules out the possibility of compression as the cause of vision loss. For sinus problems, CT with or without contrast is more appropriate [4]. 
Sinusitis is a rare but treatable cause of optic nerve injury and vision loss. One must consider optic neuropathy due to sinusitis in patients who have clinical evidence of optic neuritis with atypical features such as a history, any symptoms of sinus disease, and vision loss progression beyond 2-3 weeks. In the context of such a vision loss with paranasal sinusitis symptoms, a relationship between the two entities should always be considered and never dismissed as coincidental.

CT scans facilitate visualization of the sphenoethmoidal boundary and its relationship with the optic nerve. Anatomical configurations that predispose the optic nerve to injury include two types of nerve courses: the first is adjacent to the sphenoidal sinus, causing indentation of the sinus wall, and the second is through the sphenoid sinus, with total or partial dehiscence of the nerve [5]. This configuration should be always sought out so that ophthalmologic symptoms can be connected to the correct diagnosis in order to find the best treatment.

\section{Statement of Ethics}

The authors have no ethical conflicts to disclose.

\section{Disclosure Statement}

This research received no specific grant from any funding agency in the public, commercial, or not-for-profit sectors. None of the authors has any proprietary interest in the development or marketing of any products mentioned in this paper.

\section{References}

1 Jung JJ, Baek SH, Kim US: Analysis of the causes of optic disc swelling. Korean J Ophthalmol 2011;25:3336.

2 Balcer LJ, Prasad S: Abnormalities of optic nerve and retina; in Daroff RB, Fenichel GM, Jancovic J, Mazziotta JC (eds): Bradley's Neurology in Clinical Practice, ed 6. Philadelphia, Elsevier Saunders, 2012, pp 172-175.

3 Chafale VA, Lahoti SA, Pandit A, Gangopadhyay G, Biswas A: Retrobulbar optic neuropathy secondary to isolated sphenoid sinus disease. J Neurosci Rural Pract 2015;6:238-240.

4 Cyriac JT, Cherian T, Hadi WA, Jose J: Optic neuropathy due to allergic fungal rhinosinusitis. J Neurosci Rural Pract 2011;2:180-182.

5 DeLano MC, Fun FY, Zinreich SJ: Relationship of the optic nerve to the posterior paranasal sinuses: a CT anatomic study. AJNR Am J Neuroradiol 1996;17:669-675. 


\section{Case Reports in Ophthalmology}

\begin{tabular}{l|l}
\hline Case Rep Ophthalmol 2017;8:421-424 \\
\hline DOI: 10.1159/000476057 & $\begin{array}{l}\text { C 2017 The Author(s). Published by S. Karger AG, Basel } \\
\text { www.karger.com/cop }\end{array}$ \\
\hline
\end{tabular}

Del Noce et al.: Swollen Optic Disc and Sinusitis

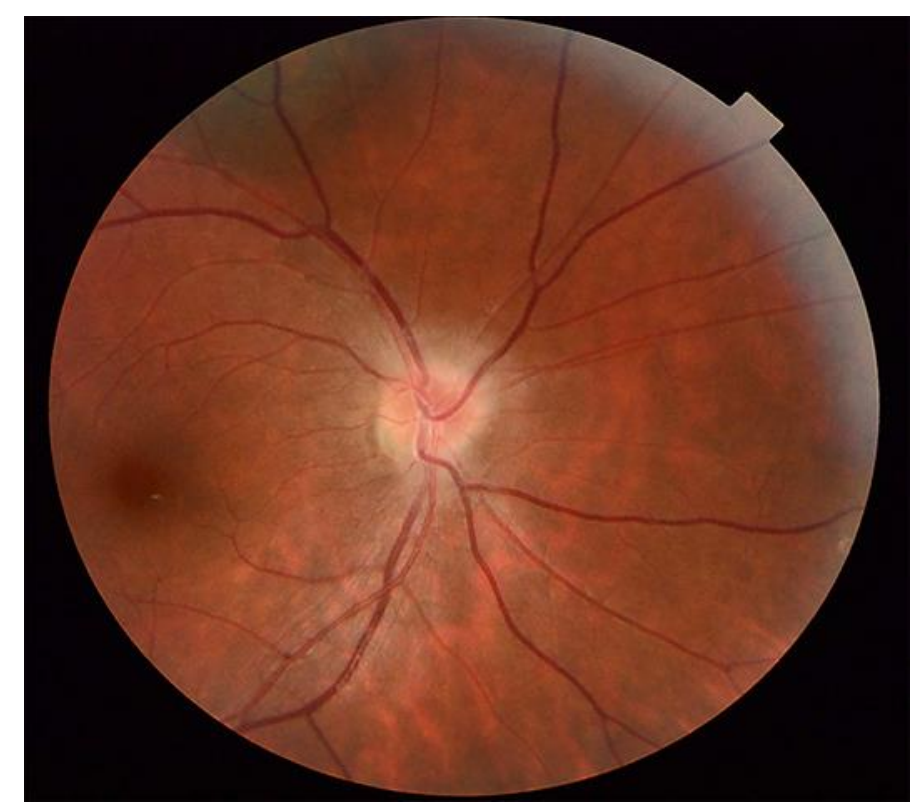

Fig. 1. Fundus examination of the right eye showed a swollen optic disc.
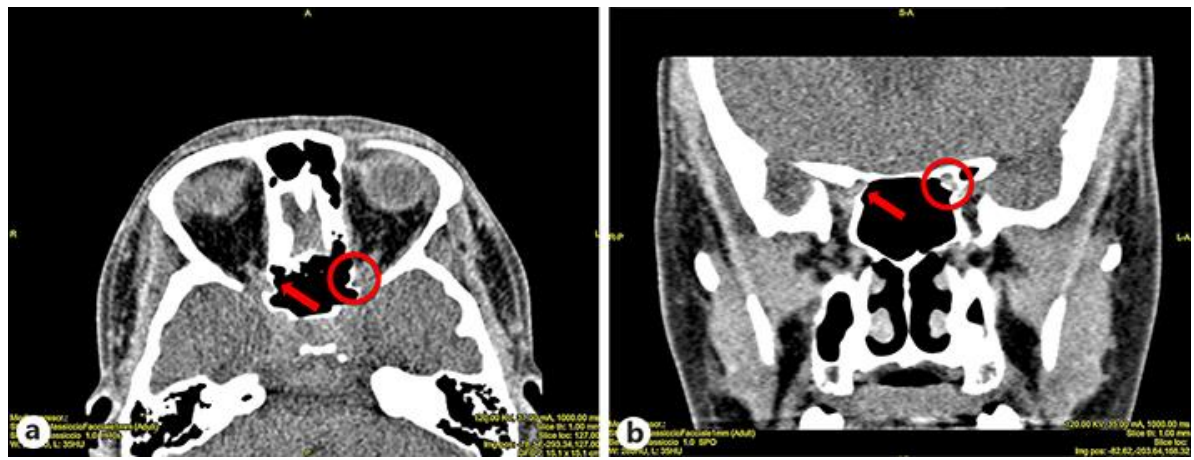

Fig. 2. Coronal (a) and axial (b) computed tomography scan of the of the facial bones showing dehiscence of the right optic nerve passing through the sphenoid sinus (red arrows). The left optic nerve passes adjacent to the sphenoid sinus and the left optic nerve close to the sphenoid sinus (red circles). 